\title{
NIVELES DE VIDA DE LOS ARRENDATARIOS DE COCHINOCA (JUJUY). ENTRE EL DOMINIO DEL MARQUESADO DE TOJO Y LA PROPIEDAD FISCAL, SIGLO XIX
}

\author{
The living standards of the cochinoca leaseholders (jujuy). \\ Their situation within the domain of the marquesado de tojo and the tax property during \\ nineteenth century.
}

\section{Cecilia Fandos*}

\section{Resumen}

Este artículo tiene como principal propósito determinar los indicadores de la riqueza personal de los arrendatarios del departamento puneño de Cochinoca, en Jujuy, a partir del registro del ganado particular del que disponían como vital recurso de subsistencia. En dos cortes históricos significativos pautados por el ejercicio de diferentes derechos de propiedad de la tierra: mientras sus pobladores eran arrendatarios de la conocida hacienda de los Campero (del Marquesado de Tojo), durante la década de 1860, y en el momento en que conservando igual condición entablaron relación contractual con el Estado, una vez que esas tierras fueron expropiadas por el fisco (luego de 1876). El examen central se afirma en el enfoque de los estudios históricos sobre los niveles de vida, determinando patrones de desigualdad social y rangos de acumulación, desacumulación y/o mera subsistencia de este universo.

$<$ Distribución de riqueza $><$ Arriendos $><$ Derechos de propiedad $><$ Siglo XIX $>$

\begin{abstract}
The aim of this work is to determine the indicators of personal wealth of the leaseholders of Cochinoca, in the Puna of Jujuy. In order to do so, I will analyze the register of their personal livestock in two different moments which, in turn, are shaped by different types of land ownership rights. First, when the residents of Cochinoca were the leaseholders of the well known Campero's property (from the Marquesado de Tojo), during the decade of the 1860's. Secondly, the period in which they established contractual relationships with the State, a moment in which they maintained the same condition despite the lands were expropriated (i.e., after 1876).

I will resort to the theoretical framework of the historical studies on living standards, which focus on patterns of social inequality and levels of accumulation, as well as decumulation, or the simple subsistence means of this universe.
\end{abstract}

$<$ Wealth distribution $><$ Leases $><$ Property Rights $><$ Nineteenth Century $>$

Recibido: 20/05/2016 // Aceptado: 31/08/2016

\footnotetext{
"Doctora en Historia. UNIHR/ISHIR-CONICET-UNJu. cecifandos@gmail.com
} 
Fandos. Niveles de vida de los arrendatarios de Cochinoca (Jujuy). Entre el dominio del Marquesado de Tojo...

\section{Introducción}

A fines del siglo XIX, como correlato de la fuerte concentración de los recursos y los factores productivos que adoptaba el modelo de consolidación de las estructuras capitalistas en Jujuy, el paisaje social rural estaba signado por la presencia de productores sin tierra propia. Efectivamente, la propiedad de la tierra era un privilegio minoritario en este escenario agrario y su contracara, la existencia de una enorme masa de arrendatarios. Del examen que surge de los datos proporcionados por el Censo Nacional de 1914, el $88 \%$ de las explotaciones productivas de la provincia norteña se orientaban a la cría de ganados, de las cuales el 60\% comprendía tenencias en arriendo; en las parcelas de uso agrícola (un $12 \%$ restante de las unidades censales), la propiedad predominaba y un $48 \%$ estaba a cargo de arrendatarios. ${ }^{1}$

Particularmente, en el agreste ambiente de la Puna jujeña su población compartió mayoritariamente esa condición ocasionando un prototipo distintivo de relaciones sociales y de producción durante el siglo XIX. Allí el sistema de arriendos se fundó principalmente en la crianza y pastoreo de animales, el pago anual de derechos de pastaje y prestaciones de servicios personales a los propietarios de las tierras:

En estos lugares de la Puna y en su totalidad el suelo y el clima se presentan para la agricultura peor, todos los moradores como se sabe se dedican a la cría de la hacienda lanar, cabrío, llamar y asnal, de lo cual los propietarios de fracción de campo cobran anualmente por hacienda lanar y cabrío el ciento 6 a 8 pesos por arriendos para pastar, y asnal y llamar por cabeza cincuenta centavos, además tienen otro impuesto llamado obligación que es el $15 \%$ el que se satisface por medio de trabajos manuales. ${ }^{2}$

La categoría de "arrendero"-como se llamó localmente a los colonos de las haciendas- quedó inexorablemente inscrita, en la visión de propios y ajenos, en relaciones de dominación y de explotación, propiciando hacia fines del siglo XIX una generalizada imagen de miseria y pobreza en la situación cotidiana de vida de estos sectores. Seguramente, los patrones de significación de la pobreza como la propia realidad fueron modificándose a luz de los procesos decimonónicos. Antes de traspasarse la mitad del siglo, todavía era punto de discusión si la Puna y sus habitantes tenían una mejor capacidad contributiva como para merecer la gravitación de un impuesto exclusivo;

\footnotetext{
1 Las unidades de producción primaria de Jujuy registradas fueron 6.632. El censo incluyó en su encuesta una pregunta sobre el principal destino (ganadero/ agrícola) de las unidades productivas. Como resultado en Jujuy se consignaron 5.825 explotaciones ganaderas, de cuáles estaban a cargo de arrendatarios 3.521; y 897 explotaciones agrícolas, con 385 de ellas en arriendo (Tercer Censo de la República Argentina (1919), año 1914. Tomo V, Buenos Aires, Taller Gráfico de L. Rosso y Ccía. pp. 80 y 823; Tercer Censo de la República Argentina (1917), año 1914. Tomo VI, Buenos Aires, Taller Gráfico de L. Rosso y Ccía. pp. 727 a 729 ).

2 Archivo Histórico de Jujuy (en adelante AHJ), Fondo Caja de Expedientes, Expte. № 7 v, año 1913, Cochinoca, 23 de octubre de 1913.
} 
la capitación pactada con los vecinos de esta región en 1840 para ser exceptuados del enrolamiento en las milicias provinciales. ${ }^{3}$ Los distintos discursos emitidos (petitorios elevados por los indígenas de la zona, informes oficiales, notas de viajeros) pasada esa mitad del siglo contienen pocas vacilaciones a cerca de las carencias y penurias de esta población en su conjunto.

Durante el siglo XIX, estos pobladores de la Puna sufrieron paulatinamente varias "pérdidas": su gente, sus tierras y sus ganados. El tradicional comercio colonial que alimentaba a los centros mineros andinos presentó dislocaciones. Paralizado durante las guerras de la independencia, a mitad del siglo XIX, la demanda minera de Bolivia había reactivado la exportación de ganado para carga y alimento de estos centros, marcando una etapa de fortalecimiento de los flujos mercantiles. También fue propicio el lapso de la Guerra del Pacífico (1879-1883) dado que la pérdida de Bolivia de su litoral marítimo favoreció momentáneamente al Norte argentino como corredor de tránsito de las exportaciones e importaciones del país limítrofe. Pero cerrado ese ciclo, algunas fuerzas (redes ferroviarias, políticas monetarias) actuaron en sentido centrífugo provocando el desplazamiento definitivo de los patrones del comercio heredados desde la colonia (Langer y Conti, 1991).

Otro registro de la situación de la Puna jujeña, además del comportamiento de los mercados, acentúa el peso de factores endógenos tales como las interrelaciones entre eventos climáticos, comportamientos demográficos y derrotero económico. Gil Montero acuña el concepto de una precarización creciente de estas sociedades en el siglo XIX, expresada en la pérdida relativa de la importancia de su población y su economía. Según esta autora, la población llegó a un pico máximo a fines del siglo XVIII y por un siglo mantuvo esos valores, revelando estancamiento. Los fenómenos centrales responsables de ese ritmo fueron las guerras, las sequias y las epidemias. En 1806 una sequía regional afectó la producción minera de Potosí y la provisión de insumos desde los centros productores aledaños. Se sucedieron luego la Guerra de Independencia y la de la Peruano- Boliviana en el trascurso de la década de 1830, incidiendo directamente en los pastos y el número de ganado producido en la región. Un momento de adversidad climatológica resultó la década de 1860, época para la cual la autora registró una sequía y su consecuente efecto en la preservación del principal medio de subsistencia de los campesinos puneños: el ganado. Paralelo a ello se propagó una epidemia de carácter regional. Nuevos momentos críticos fueron la coyuntura de sublevación y de enfrentamiento armado de mediados de la década de 1870, y la propagación de la difteria provocando mortalidad en la población a comienzos de la década de 1880 . Todos estos ciclos indujeron dos tendencias fundamentales del comportamiento demográfico local:

\footnotetext{
3 Gil Montero, 2005, 167- 169. Según la autora, al momento de discutirse la abolición de este tributo personal (1851) se desató un debate sociológico y económico en la legislatura local implicando dos posturas sobre las condiciones de estos pobladores; la parte aglutinada en la continuidad del mismo subrayó que gozaban de una mejor situación económica y de mayores riquezas que los habitantes de los valles, mientras los abolicionistas apuntaban que eran insolventes y dependientes de una actividad pastoril menguada en sus posibilidades para esa época.
} 
Fandos. Niveles de vida de los arrendatarios de Cochinoca (Jujuy). Entre el dominio del Marquesado de Tojo...

estancamientos por emigración y mortalidad; y la creciente feminización (Gil Montero: 2006, 389-391).

Por su parte, la configuración del nuevo orden institucional del Estado republicano arroja un balance negativo en cuanto a su incidencia en estas comunidades. Además de la alteración que provocó la consagración del derecho de propiedad privada en el control de los recursos, un aspecto que reviste suma importancia es la nueva estructura fiscal e impositiva proyectada por el flamante Estado. Los nuevos gravámenes implementados fueron la contribución territorial, extracción de sal, capitación indígena y contribución del 5\% del producido por bienes muebles, además de la novel fiscalización de la aduana entre territorio argentino y boliviano (Madrazo: 1989, 151; Gil Montero: 2006, 387). Cada uno de ellos, directamente o por transferencia de los propietarios, recayeron en los principales productos de consumo, de intercambio o de la renta que debían afrontar los sectores campesinos.

Con este panorama como telón de fondo en el siglo XIX el saldo definitivo, ya avanzado el siglo XX (desde finales de la década de 1920), fue una creciente proletarización de la población arrendataria; proceso que se liga a la dinámica de los polos capitalistas de la provincia, como la agroindustria azucarera primero, la minería de gran escala luego (Rutledge, 1987).

La provisión de mano de obra a través del arrendamiento fue corriente ya en algunas haciendas de la región desde la época colonial (Palomeque: 2000; Sica: 2014). ${ }^{4}$ En la Puna jujeña, además de sus diversidades ambientales y de sus peculiares especializaciones productivas, ${ }^{5}$ las poblaciones indígenas quedaron claramente diferenciadas por las formas de acceso a la tierra durante la colonia. Por un lado, los indios encomendados de Casabindo y Cochinoca, integrados al complejo económico del Marquesado de Tojo, gozaban de pleno derecho a la propiedad comunal, por su condición de originarios. Por otro lado, las poblaciones indígenas no encomendadas, eran "forasteros sin tierras", asentados en haciendas privadas mediante el sistema de arrendamiento. Según Gil Montero, a fines del siglo XVIII "dos de cada tres indígenas de la Puna carecían de derechos sobre las tierras", siendo arrendatarios (Gil Montero: 2006, 392).

El perfil se profundizó, se generalizó y se constituyó con los atributos antes citados en los tiempos republicanos. Entonces "los indígenas, antes originarios y

\footnotetext{
${ }^{4}$ Madrazo, siempre remitiendo al caso en el que profundizó su estudio, reconoce que las haciendas andinas jujeñas ya basaban sus relaciones de producción en el arrendamiento desde el siglo XVIII (Madrazo: 1995, 141).

5 Albeck y Palomeque diferencian al menos cuatro subregiones en la Puna jujeña: I. Septentrional (actual Yavi, zona más húmeda y templada, ganadera y con mayor desarrollo de la agricultura -cultivos de alfalfa, papas y quinuas-); II. Centro- Occidental (departamentos de Santa Catalina y Rinconada; área más seca y poco propensa para agricultura, desarrollo del pastoreo de ganado en zonas de lagunas y de textiles, fueron importantes centros de actividad minera (lavaderos de oro) y comercial en el siglo XVIII); III. Centro- oriental (con las poblaciones actuales de Casabindo y Cochinoca, con importante producción ganadera y de textiles); IV. Meridional (con ambiente de salares, regular desarrollo de la ganadería, sin agricultura, originario asentamiento de la reducción de Casabindo y Cochinoca) (Albeck y Palomeque: 2009, 176- 1776).
} 
forasteros con sus enormes diferencias internas, eran vistos como una masa homogénea de campesinos arrendatarios sin muchas distinciones" (Gil Montero: 2006, 394). Los que ya pagaban arriendos desde la colonia siguieron haciéndolo a partir de la Independencia. Los indígenas con propiedad comunal transmutaron en arrenderos, perdiendo indefectiblemente sus derechos a la tierra.

El fenómeno ha sido objeto de una prolífera indagación y producción historiográfica, fue principalmente explorado a partir de la unidad productiva que lo sostuvo: la hacienda de arrendatarios en vinculación al proceso de desintegración de las comunidades indígena y el despojo y acaparamiento de sus tierras (Madrazo, 1982); la reconstrucción de las estructuras agrarias y la dinámica de reconfiguración de los derechos de propiedad (Teruel 2005 y 2014), las estratificaciones y desigualdades sociales consecuentes de las formas de tenencia y de acceso a la tierra (Fandos, 2013; Fandos y Parolo, 2011); el rol protagónico de estos actores en las recurrentes acciones de resistencia y movimientos de lucha campesina (Paz, 1991).

Este estudio vuelve a poner el centro de atención en los arrendatarios de la Puna jujeña, esta vez en el territorio de Cochinoca, en dos momentos discordantes; con el propósito general de contribuir al conocimiento sobre las condiciones materiales de existencia de este universo social, desde la perspectiva de los estudios sobre el nivel de vida. La tarea principal apunta, en primer término, a construir indicadores de riqueza personal a partir del registro del ganado particular del que disponían como vital recurso de subsistencia. En segundo término, examinar y reconocer a partir de ellos niveles de desigualdad social y estimar rangos de acumulación, desacumulación y/o mera subsistencia. Paralelamente, nos proponemos efectuar una comparación de la riqueza ganadera en dos cortes temporales históricamente significativos, ceñidos a las modificaciones sufridas en los derechos de propiedad en la zona. Por un lado, mientras los pobladores de Cochinoca eran arrendatarios de la conocida hacienda de los Campero, propiedad integrada al Marquesado de Tojo, durante la década de $1860 \mathrm{y}$, por otro lado, en la década de 1890, momento en que esas tierras ya habían sido expropiadas por el fisco y los mismos sujetos pasaron a ser arrendatarios del Estado, luego de 1876. Una hipótesis central que guía la indagación es que pese a mantenerse invariable el status de arrendatarios a lo largo de toda la etapa, la experiencia del dominio fiscal mitigó por un tiempo la opresión y el peso del sistema en algunos aspectos, aunque desconocemos si ello se tradujo en una mejora objetiva de su situación económica. Por ello, también reseñamos una secuencia de la normativa, de las prácticas sociales y de las representaciones simbólicas derivadas de estos contratos y formas de explotaciones rurales.

\section{Los niveles de vida como campo historiográfico. Las fuentes y los indicadores}

El costado de análisis escogido para poner en la mira a la masa de arrendatarios procede en buena medida del enfoque de los estudios históricos sobre los niveles de vida. Esta vertiente remite a un amplio campo historiográfico, enraizado en distintas tradiciones. Los estudios del marxismo británico desde mediados del siglo XX pueden 
Fandos. Niveles de vida de los arrendatarios de Cochinoca (Jujuy). Entre el dominio del Marquesado de Tojo...

tenerse como referentes de esta línea de indagación, cuando cobró centralidad el tema de las condiciones económicas y sociales de las clases trabajadoras durante el proceso de la Revolución Industrial. La abrumadora demostración empírica de Hobsbawm en la polémica seguida sobre la situación de la clase obrera inglesa constituyó una primaria agenda de los indicadores históricos que este tipo de estudio debía procurar: no solo índices de salarios sino también demográficos, de consumo, de endeudamiento y tasas de mortalidad, esperanza de vida, etc. (Hobsbawm, 1979). Si la obra de Hobsbawm amplió el horizonte del tema incorporando además de lo económico "lo social", Edward Thompson tuvo la virtud de introducir "lo cultural" (Thompson, 1984).

Estas directrices principalmente orientadas a develar origen, identidad y condiciones de los sectores obreros fueron proyectándose sobre las poblaciones rurales, siendo muy prolífica en la historiografía agraria inglesa (Dyer, 1998). Por su parte, la indagación en el mundo ibérico es más tardía, incipiente en la década de 1980, hizo explosión en los años 90 como un reguero de la discusión de fondo sobre el papel desempeñado por la agricultura en el desarrollo económico, social y político de la España contemporánea (siglos XIX y XX).

Al promediar el siglo XX, un primer balance del cauce corrido subraya la múltiple dimensión que ha adquirido la propuesta, pudiéndose agrupar dos vertientes: las que apuntan al poder adquisitivo de las poblaciones rurales (salario, rentas, consumo, disponibilidad de bienes y mercancías) y las que se orientan a desentrañar la calidad de vida y el bienestar humano (indicadores sociales y antropométricos). Incluso desde la especulación teórica se ha buscado entroncar este tipo de pesquisas con los conceptos de "habilitación" (availability) y de "capacidades" de Amartya Sen (Martínez Carrión, 1997). Se trata de categorías aportadas por el economista para reformular la noción de bienestar en la querencia de las ciencias sociales. Las "habilitaciones" son los recursos (simbólicos y materiales) en dominio del sujeto, término que desde el interés sociológico remite necesariamente a una relación de poder; por su parte las "capacidades" aluden a las ventajas y a las oportunidades de las personas, ${ }^{6}$ simbolizando las posibilidades que tienen éstas de alcanzar desempeños valiosos. Traducido a términos de la investigación histórica, el desafío apunta a desentrañar la percepción que la propia gente tenía de riqueza, de bienestar y del goce de la felicidad.

Entre los múltiples indicadores y factores que ponderan los estudios sobre el nivel de vida en las sociedades rurales y más específicamente en los grupos campesinos adoptamos en este estudio uno de orden material, como es el grado de desigualdad producto de la distribución de riqueza; y enfatizamos en el trabajo el plano institucional, asociado a los derechos de propiedad y las estructuras de explotación de la tierra.

Respecto de los indicadores, continuamos un procedimiento ya escogido en otra ocasión (Fandos, 2016) consistente en la estimación de riqueza de campesinos

${ }^{6}$ El término de habilitación apunta a la idea de "derecho a algo", en el sentido de autorización formal, quizás legalmente establecida (Córdoba, 2007). Mientras el uso de "capacidades" la emplea desde la acepción griega de "dunamis", de aquellos aspectos humanos que pueden traducirse en potencialidades o capacidad para existir o actuar. 
arrendatarios de la finca de Cochinoca, a partir de considerar el ganado como el principal capital del que eran propietarios estos productores directos, además de componente central de su dieta alimenticia, bien de intercambio y medida del pago de sus rentas. Para ello hemos analizado dos listados, a modo de tomas fotográficas comparables entre sí, que nos informan acerca de la propiedad de ganado de cada poblador de este distrito: uno del año 1864, cuando la totalidad de ellos eran arrendatarios de la familia Campero; el otro corresponde a las cédulas censales del censo nacional de 1895 donde se registra este dato para todos los productores y criadores de ganado de la extensa finca, ya propiedad fiscal.

La información de 1864 organiza los datos de un censo local conteniendo el nombre y la edad del titular de cada familia, el de su cónyuge si fuera casado o la condición de viudez si este fuera el caso, el de sus hijos y agregados, y el número de cabezas de ganado lanar, caprino, llamar y vacuno que cada cual disponía. Todos estos datos se alistan distinguiendo los diversos poblados que entonces constituían el departamento de Cochinoca. ${ }^{7}$ El examen principal que se persigue es la indicación de la distribución de riqueza personal, para comparar luego con los parámetros de la década de 1890. El documento suministra una valiosa información sobre la propiedad de ganado de cada grupo familiar - y es la única fuente del tipo con la que contamos- , pero es factible que haya operado con subregistros si tenemos en cuenta lo siguiente. El anterior relevamiento de población de Cochinoca es de 1859 y consigna un total de 2.622 habitantes; el posterior corresponde al primer censo nacional, en 1869, y establece un total de 3.845 individuos, mientras en 1864 se anotan 1.599 pobladores. No obstante, el momento de este censo también coincide con la etapa final de un ciclo demográfico crítico, por mortalidad y emigración. Gil Montero alude a esta coyuntura específica provocada por sequias y una epidemia regional propagada entre 1861-1862; también expresada en una fuerte caída de los índices de masculinidad (Gil Montero, 2004).

Para el corte de la década de 1890 se trabajó con los listados de los productores ganaderos que proporcionan los boletines de ganadería, del censo nacional de 1895, indicando para cada uno el número de cabezas que les correspondía por especie, contemplando solamente los siguientes rubros: ovinos, caprinos, vacunos, asnal y camélidos ( in considerar mulares, caballares, entre otros).

Como nos interesaba indagar la distribución a nivel de riqueza y no por tamaño de las crías, hemos traducido en valor de mercado los distintos números de animales para estimar el "capital ganadero" con los siguientes precios, adoptando las cifras que proporciona Madrazo (1989) para la década de 1860: ovejas (dos pesos bolivianos), vacunos (16 pesos bolivianos), burros ( 8 pesos bolivianos) y llamas (5 pesos bolivianos).

\footnotetext{
7 En ese momento la jurisdicción del Moreno era parte de este departamento, pero luego se anexionó al de Tumbaya, por esa razón no ha sido incluido en el análisis a fin de no desvirtuar la comparación con la década de 1890. No es la primera vez que se trabaja este interesante documento, Madrazo fue el pionero y le sirvió para efectuar un estudio de la disponibilidad de bienes, trabajo y consumo por unidad familiar, siguiendo el modelo demográfico campesino de Chayanov (Madrazo: 1989, 185-190). También Gil Montero lo incluyó en sus investigaciones sobre la interrelación entre la economía, las condiciones ambientales y la demografía de la Puna (Gil Montero, 2004).
} 
Fandos. Niveles de vida de los arrendatarios de Cochinoca (Jujuy). Entre el dominio del Marquesado de Tojo...

Respecto a fines del siglo XIX, hemos venido usando los precios vigentes en 1903 proporcionados por un texto de esa época. No obstante, se han consultado fuentes testamentarias de la década de 1890 obteniendo los siguientes valores promedio: 25 pesos nacionales por cada vaca, tres pesos por cada oveja, cuatro pesos por cada cabra, 12 pesos por cada burro y seis por cada llama. ${ }^{8}$ Finalmente, para evaluar la riqueza ganadera y obtener escalas de distribución hemos computado el Gini como índice de desigualdad.

También hemos procurado trazar un cuadro del tamaño de las crías de animales estimables para sortear líneas de pobreza, alcanzar niveles de subsistencia y/o de rentabilidad. Una primera base de medición procede de los rangos de pobreza de las familias indígenas de la Puna estipulados al inicio del siglo XX por el Estado, quien consideraba en tal situación a aquellas que no fuesen propietarias de las parcelas de producción y que no alcanzaban las cincuenta cabezas de ganado menor. ${ }^{9}$ Otra comprobación proviene de un proyecto de ley provincial de 1892 sobre regulación de obligación de conchabo a vagos y arrendatarios, delimitando como tales a los sujetos que no poseían ganados o cultivos suficientes para costearse su subsistencia y la de sus familias. Ese universo quedó pautado para todo arrendatario que reuniera menos de 100 cabezas de ganado mayor y/o menos de 300 de ganado menor. ${ }^{10}$ Finalmente, otra medida complementaria de la última es la que surge de información contemporánea sobre crías de animales mínimos rentables para la práctica del pastoreo ovino en la Puna. Esta decisión metodológica obedece a que en líneas generales los estudios actuales sobre pastoreo de animales describen técnicas y prácticas muy semejantes a las que se empleaban a fines del siglo XIX y comienzos del siglo XX: actividad familiar, escaso nivel de tecnologías y maquinarias modernas aplicadas, lazos comunitarios (reciprocidad, cooperativas) (Tomasi, 2013; Reboratti, Arzebo, Castro, 2003-2004). Así, resulta que desde las 300 cabezas, una majada de ovinos permite márgenes de rentabilidad en estos ambientes (Teruel, 2005).

Las jerarquizaciones sociales en términos de riqueza permiten tratar globalmente los bienes económicos, no por su tamaño sino por su valor, pudiendo por ejemplo salvar las dificultades derivadas de un estudio de estructuras agrarias basado en la extensión de los predios, donde muchas veces una propiedad de 1.000 hectáreas significa económicamente hablando mucho menos que una granja de cinco hectáreas al lado de una estación de trenes. Y también nivela en un valor monetario la riqueza ganadera y la procedente de la propiedad de la tierra, que por lo general se omite al

8 Holmberg, 1904. Archivo Histórico de Tribunales de Jujuy (en adelante AHTJ), Fondo Expedientes Juicios Universales -sucesorios-: Año 1897, Inventario de Brígida Jurado, $N^{\circ} 130$; Año 1895, Inventario en Finca El Aparejo, $N^{\circ} 50$; Año 1895, Inventario de Lorenzo Quipildor, $N^{\circ} 3$; 1894, testamento de Catacata, $N^{\circ} 140$; Año 1891, inventario de Catacata, $\mathrm{N}^{\circ} 102$; Año 1897, sucesorio de Ramón Fascio, $\mathrm{N}^{\circ} 4$.

9 AHJ, Fondo Registro Oficial de Leyes, Ley N 116, agosto 25 de 1906, fs. 504; AHJ, Fondo Registro Oficial de Leyes, Reglamentación de la Ley de agosto 25 de 1906, 8 de noviembre de 1906, fs. 542.

${ }^{10}$ Archivo Histórico de la Legislatura de Jujuy (AHLJ), Fondo Cajas Documentos, No 48, año 1892, Ley sobre vagos y arrenderos, 12 de enero de 1892. 
analizar únicamente tamaños de las crías y superficies de los predios, pues esos datos así consignados impiden sus cotejos.

Por otro lado, perseguimos como trasfondo del análisis los posibles impactos de las modificaciones sufridas en los derechos de propiedad y las estructuras y prácticas de explotación de las unidades de arrendamiento, preguntándonos en qué medida ellas se reflejaron en el nivel de vida del universo de análisis. Sabemos que ello implica un recorte sustancioso de las variables de peso a considerar, pero igualmente válido de llevarse a cabo. De acuerdo al balance historiográfico del tema para los estudios agrarios de España, hay tres componentes centrales del análisis de calidad de vida en sociedades históricas rurales: el medio ambiente, los mercados y las instituciones. Respecto a este último, las normas jurídicas y las prácticas que reglan el uso y la distribución de la tierra tienen una incidencia directa, porque las distintas formas determinan los sistemas de trabajo, el aprovechamiento de los recursos y la riqueza individual (Martínez, Carrión, 1997). La experiencia desarrollada por el campo historiográfico español concedió central atención a las llamadas reformas liberales del siglo XIX (abolición de mayorazgos, diferentes amortizaciones, cercamientos, anulación de bienes propios y propiedades comunales) como mirador de los niveles de vida campesinas. En esa línea de ponderación de los factores institucionales en el asunto, Pérez Picazo (2010) amplia la apuesta más allá de los derechos y las estructuras de propiedad, para concentrarse igualmente en los regímenes de tenencia de las explotaciones, tipos de contratos, la orientación rentística o productivista de los dueños de la tierra, la autosubsistencia y/o la mercantilización la explotación campesina.

Afirmados en estos lineamientos teóricos/ metodológicos, desarrollamos a continuación una revisión bibliográfica de las formas de propiedad y de explotación de Cochinoca a fin de contextualizar y problematizar nuestro análisis, para centrarnos luego en los resultados del estudio de distribución de riqueza.

\section{El espacio social rural de Cochinoca. Un breve recorrido por las estructuras de propiedad, los sistemas de arriendos, la producción y los mercados}

Según la literatura existente, la unidad productiva típica que arraigó a la masa de arrendatarios de los territorios de la puna jujeña durante el siglo XIX fue la hacienda de arrendatarios. La misma se configuró en los inicios de los tiempos republicanos como conclusión de varios factores desplegados con la Independencia. Principalmente, la declinación de los mercados mineros altoperuanos al recortar paulatinamente los ritmos y los niveles de demanda de las áreas agropecuarias abastecedoras, entre ellas la jurisdicción de Jujuy. Desatando simultáneamente una reconversión de las grandes propiedades de origen colonial, que se habían organizado en torno al control de mano de obra indígena (encomendada y no encomendada), la producción ganadera y el comercio articulado con ese mercado, en explotaciones ponderativas de la acumulación de tierras como vital factor y de la renta como principal beneficio económico. Proceso que redundó, a su vez, en la avanzada territorial de estos grandes propietarios, despojando y usurpando a los campesinos con derechos comunales. En consecuencia, esos cambios 
Fandos. Niveles de vida de los arrendatarios de Cochinoca (Jujuy). Entre el dominio del Marquesado de Tojo...

compelieron a la población natural de la región a la generalización del arrendamiento como principal forma de acceso a la tierra (Madrazo, 1989).

Haciendo un testeo de los interrogantes que introduce Mörner para estudiar los sistemas de colonatos en América Latina (en todas sus variantes: arrendamientos, aparcería, inquilinatos, terrazgueros, etc.), ${ }^{11}$ estamos en condiciones de afirmar que en el caso tratado el arrendamiento fue funcional al interés de maximización de ganancias de los propietarios, quienes adoptaron una estrategia netamente rentística para explotar sus propiedades, en una coyuntura de quiebres de mercados, declinación económica, abolición de otras formas de trabajo (encomiendas y tributo) y de reformas institucionales (desamortización de la propiedad comunal) que les facilitaban la circulación y el acceso a más tierras.

En la visión de Madrazo, todo el sistema redundó en una conducta propietaria de sobreexplotación con la intención de sacar el máximo jugo al negocio rentístico, provocando condiciones de infrasubsistencia en la masa campesina arrendataria o pequeña propietaria; a la postre, induciendo a estos grupos a la proletarización progresiva (Madrazo: 1986, 165-167).

El quiebre de la rentabilidad de las haciendas de la zona a lo largo del siglo XIX también es un tópico que subraya Rutledge, pero con un razonamiento distinto al de Madrazo. Deduce que fue la sistemática resistencia ofrecida por los arrendatarios desde mediados del siglo XIX lo que minó los beneficios del sector terrateniente/ rentístico, provocando caídas en las remuneraciones del sistema hacendario; "los indígenas no solo continuaron provocando agitaciones para que las tierras fueras devueltas a sus comunidades, sino que además, según parece, mantenían las rentas que debían pagar a un nivel tan bajo, que la viabilidad económica del sistema de hacienda llegó a verse amenazado" (Rutledge: 1987, 182). En suma, esa situación se hizo tan patente al finalizar la década de 1920 que obligó a muchos terratenientes a buscar alternativas en la administración de sus alicaídos negocios rentísticos, basados en los tradicionales contratos con los arrendatarios indígenas. Así, para esa época y en esa búsqueda fue que los sectores propietarios comenzaron a vender o alquilar sus tierras a los ingenios azucareros, forzando a las poblaciones allí establecidas a servir como mano de obra en esa actividad agroindustrial (Rutledge: 1987, 194).

Con ese encuadre historiográfico de la problemática inscribimos nuestro caso de estudio, la finca de Cochinoca, esencialmente una típica hacienda de arrendatarios. Su historia se ligó desde la época colonial al "Marquesado de Tojo", una gran empresa familiar, constituida por el control de un conjunto de tierras de amplia diversidad ecológica, situadas en Tarija y la Puna argentina, fundada institucionalmente en la encomienda, el mayorazgo y la titulación nobiliaria. A comienzos del siglo XIX el

\footnotetext{
${ }^{11}$ Puntualizando cuestiones como "¿De qué modo se ha relacionado el surgimiento del sistema con el acceso a la tierra, al capital y a la mano de obra? ¿Qué formas alternativas de trabajo existían? ¿Fue el objeto de los terratenientes, cuando introdujeron el sistema, rebajar los costes de producción durante un período de baja? ¿O, por el contrario, manifiesta su deseo de asegurarse trabajo suplementario estable en una época de alza económica? ¿Es el grupo trabajadores en cuestión principalmente un producto de elevación o de descenso de movilidad social? [...]" (Mörner: 1970, 10).
} 
patrimonio de esta familia se extendía sobre todo el departamento de Cochinoca, una parte mayoritaria de Yavi y algunas porciones de Santa Catalina en Jujuy (Madrazo, 1989; Teruel, 2016).

Por su parte, el distrito de Cochinoca se asentó en los límites del colonial pueblo de indios homónimo y de Casabindo, establecidos entre 1573 y 1602 cuando ambas parcialidades étnicas obtuvieron paralelamente derechos de propiedad comunal. Otro hito colonial de relevancia fue la constitución de la encomienda sobre esta población indígena, en 1654, de manos de Pablo Bernárdez de Ovando. Por su descendencia, esta encomienda se unió a la propiedad de los marqueses de Tojo, desde 1700, fecha en que Juan José Campero y Herrera (yerno y heredero de Ovando), adquirió el título nobiliario.

Con el paso a la etapa republicana la familia Ovando-Campero sostuvo y ostentó derechos de propiedad sobre el predio comunal de los pueblos de Casabindo y Cochinoca. Respaldados y afirmados en la postura de que la encomienda figuraba derechos de propiedad sobre la tierra fue que estos actores transfiguraron de hecho las antiguas obligaciones de sus tributarios en pago de arriendo, hasta la década de 1870 . El sistema se basaba, para entonces, en el arrendamiento de pequeñas fracciones por las que se pagaba en "proporción a la estención (sic) del terreno y en el número de haciendas que pastorean, de la siguiente manera: por el ciento de ovejas 1 peso 75 centavos por año, y por animales grandes como caballos, burros, etc., 25 centavos los que producen una renta como de 8.000 pesos bolivianos". ${ }^{12}$

Ese costo implicaba casi una duplicación de la renta pagada a mediados del siglo XIX, cuando lo usual fue medio real por cabeza de ganado mayor y solo un peso cada cien ovejas y cabras (Madrazo: 1989, 163). Una explicación ofrecida a esa escalada, principalmente en el ganado menor, es la que sostiene que la gravitación de la implementación del impuesto a la propiedad de la tierra desde 1854 incidió directamente, ya que los dueños de las mismas inmediatamente lo trasladaron al precio del arriendo: subieron de un peso a 1,25 las cien cabezas de lanares y caprinos, y un real los del tipo mayor (Madrazo: 1989, 165).

A partir de 1872 los arrendatarios iniciaron acciones tendientes a cuestionar la legitimidad de los títulos de propiedad de los Campero, desatando una oleada de rebeliones en los campesinos de la Puna. El desenlace inicial de este conflicto fue el conocido fallo de la Corte Suprema de Justicia de 1877 por el que se declararon fiscales estas tierras. En esta nueva fase, de propiedad pública, el acceso a la tierra estuvo mediado por la figura del arriendo fiscal. Con ese status permanecieron hasta la década de 1890 en que algunos rodeos comenzaron a ser privatizadas mediante la subasta pública a mejor postor. Por este mecanismo fueron transferidas las tierras de Casabindo y Cochinoca a un nuevo grupo de propietarios, muchos de ellos inversionistas (mineros o del negocio inmobiliario) de origen extranjero, que reprodujeron a la postre,

\footnotetext{
${ }^{12}$ Informe de la Inspección Nacional de Agricultura en la Provincia de Jujuy, República Argentina,
} Departamento Nacional de Agricultura, 1875, p. 324. 
Fandos. Niveles de vida de los arrendatarios de Cochinoca (Jujuy). Entre el dominio del Marquesado de Tojo...

nuevamente, una estructura de gran propiedad con relaciones de producción basadas en el arriendo (Teruel, 2005).

En definitiva, la propiedad de la tierra en Cochinoca trascurrió durante todo el siglo XIX y los inicios del XX como un factor central de generación de desigualdad social. Efectivamente, recurriendo al índice de Gini como indicador de esa realidad podemos señalar que el espacio más crítico de inequidad en concepto de distribución de la tierra de todo el territorio argentino entre 1860 y 1870 fue la Puna $(0,9977)$, en general, y sobre todo Cochinoca (equivalente al máximo punto -1-, tanto en la fase privada como en la de propiedad pública) ${ }^{13}$ Esa situación extrema se atemperó con la privatización de estas tierras obradas desde los últimos años del siglo XIX, pero sin traslucirse una mejoría social general, en 1909 el mismo índice reportaba en 0,9535 (Fandos, 2013).

Los estudios existentes dividen las aguas entre la punta del proceso que implicó la reorganización de los derechos de propiedad una vez desatada la sublevación campesina de mediados de los años 70 y el epílogo de la privatización desde la finalización de la década de 1890. En el transcurso de esos años predominó el dominio público en Cochinoca, el que abarcaba una inmensa propiedad que en 1887 estaba valuada en 800.000 pesos moneda nacional, usufructuada por sus moradores mediante la figura del arriendo fiscal.

Siendo de dominio fiscal, la población de Cochinoca continuó como arrendataria de la finca, pero imperando otras reglas y otras prácticas. Al estilo completamente informal y precario que adoptó el contrato de arrendamiento en las haciendas de propiedad particular (porque no había letra escrita sobre ellos, ni determinación prefijada de los cánones, estaban reglados en la costumbre y carecían de resguardo alguno contra la decisión suprema de los propietarios), sobrevino una seguidilla de leyes en la instancia de tierras públicas que lo reglaban. Así, se mantuvo invariable la modalidad del gravamen de derecho de pastaje en proporción al número de cabezas pero ahora se precisaban las tasas a aplicar, y cada vez que estas se modificaban. Y se eliminó por completo de la reglamentación las obligaciones de servicio personal que sí exigían los propietarios.

Hemos logrado reconstruir una tabla evolutivo y comparativo que nos permite hacer algunas inferencias sobre la gravitación de la renta de arriendo en las tierras públicas.

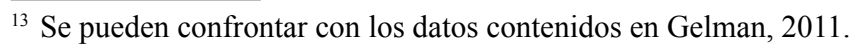


Tabla 1. Provincia de Jujuy. Valores de los arriendos entre fines del siglo XIX y comienzos del XX

\begin{tabular}{cccc}
\hline Año/Tipo & $\begin{array}{c}\text { Lanar y Cabrío } \\
\text { (por 100 cabezas) }\end{array}$ & $\begin{array}{c}\text { Asnal y Llamar } \\
\text { (por cabeza) }\end{array}$ & $\begin{array}{c}\text { Vacuno, Mular } \\
\text { (por cabeza) }\end{array}$ \\
\hline $1880 /$ Fiscal & $\begin{array}{c}\text { 6 reales } \\
(0,74 \text { peso nacional) }\end{array}$ & $\begin{array}{c}1 / 2 \text { real } \\
(0,04 \text { peso nacional })\end{array}$ & $\begin{array}{c}1 / 2 \text { real } \\
(0,04 \text { peso nacional) }\end{array}$ \\
\hline $1886 /$ Fiscal & 0,75 peso nacional & 0,14 peso nacional & 0,14 peso nacional \\
\hline $1891 /$ Fiscal & 2 peso nacional & 0,25 peso nacional & 0,30 peso nacional \\
\hline $1904 /$ Fiscal & 5 peso nacional & 0,25 peso nacional & 0,75 peso nacional \\
\hline $1911 /$ Privado & 6 peso nacional & 0,60 peso nacional & \\
\hline $1912 /$ Privado & 6 a 10 peso nacional & & 0,80 a 1 peso nacional \\
\hline $1913 /$ Privado & 6 a 8 peso nacional & 0,50 peso nacional & \\
\hline
\end{tabular}

Fuente: Elaboración propia sobre la base de Registro Oficial, Compilación de Leyes y Decretos de la Provincia de Jujuy, Tomo III (1887). Jujuy: Imprenta Tipográfica de José Petruzzeli, 381- 382, 628- 629; AHJ. Fondo Registro Oficial, 1891, fs. 246; AHLJ. Fondo Actas Manuscritas $N^{\circ} 27$, Sesión del 3 de mayo de 1904, fs. 72, Ley 88; AHJ. Fondo Caja de expedientes, año 1911, Expte. 85; AHJ. Fondo Caja de expedientes, año 1912, Expte. 124, 13 de agosto de 1812; AHJ. Fondo Caja de expedientes, año 1913, Expte. 50.

El cambio oficial que se ha tenido en cuenta para convertir los valores de moneda boliviana a pesos nacionales entre 1880 y 1886 es de 0,72 centavo peso nacional por un peso boliviano.En lo que respecta a la evolución de los precios de los arriendos fiscales, resulta claro el incremento sufrido, sobre todo en lanares (más de 500\%) y en vacunos (un 400\%), en 14 años; luego, retomando los datos antes aportados para la década de 1870 previo a la expropiación de la propiedad detentada por los Camperos (en base al cambio de 1 peso boliviano, 0,72 pesos nacionales) podemos señalar que fue recién a partir de la década de 1890 que los arriendos fiscales superaron ese canon anteriormente vigente.

Parecería desatarse una tendencia de mayor equilibrio a comienzos del siglo XX, sin fuertes contrastes, entre las rentas por arriendos percibidas en las haciendas privadas y los predios fiscales, aunque por ahora se ofrecen como cifras muy preliminares. Pese a ello, es factible advertir la construcción por parte de los arrendatarios de una idea de justeza y de equidad obrados en las parcelas de uso fiscal, en contraposición al "subido" precio de las rentas habidas por los dueños de tierras particulares, según sus propios relatos (Fandos, 2015).

Por otra parte, entre los múltiples ensayos del Estado para asegurarse el cobro de estas rentas y optimizar su administración, se trasluce entre líneas que los arrendatarios de las tierras fiscales controvertían frecuentemente la normativa, disponiendo una permisibilidad que redundaba, muchas veces, en la continuidad de ciertas prácticas como reaseguro de su subsistencia. A propósito hacemos mención particularmente a una de ellas:

Sucede que varios de los arrenderos que tienen una tropa de ganado lanar en el Rodeo A, por ejemplo, lo llevan diariamente 
Fandos. Niveles de vida de los arrendatarios de Cochinoca (Jujuy). Entre el dominio del Marquesado de Tojo...

al rodeo $\mathrm{B}$, de lo cual resulta que los pastos del rodeo $\mathrm{B}$ se consumen y se hacen insuficientes para mantener la tropa de los ocupantes de dicho rodeo [...] En esta parte sucede también que algunos de los arrenderos dicen "soy arrendero de las tierras del Estado y por consiguiente soy dueño de hacer pastar mi ganado en lugar que mejor me parezca". Este principio a mi modo de ver me parece de todo punto inaceptable, pues vendría a dar por resultado derecho de la comuna, entre unos y otros. ${ }^{14}$

Precisamente, ese "derecho de comuna" fue asediado con los procesos de privatización de las tierras a partir de la era republicana por el parcelamiento y la delimitación de la propiedad, coartando el uso de espacios múltiples y de campos comunales. En la Quebrada de Humahuaca y la Puna jujeña se practicaba la ganadería ovina y vacuna semi trashumante. Un requisito clave era la amplitud y movilidad en la disponibilidad de oferta de los pastos y las aguadas.

Aparentemente por lo explícito de la cita precedente, esas condiciones no fueron alteradas en las tierras de arriendo de propiedad fiscal, pues en la práctica no era fácil reducir los campos cedidos en rodeos demarcados. La discrepancia en ese punto con el estrechamiento de los espacios productivos que implicaba la consolidación de la propiedad privada también resultaba crucial, pues de esa forma los patrones se aseguraban "los mejores pastoreos, aguadas y vertientes y madrijones de agua [...]"; quitando del beneficio a los arrendatarios. ${ }^{15}$

La especialización productiva de la Puna fue la ganadería de autoconsumo (de la cual derivaba la carne para alimentación familiar, la lana asociada a una tradición de tejedurías, servía como principal medio de transporte y los cueros). La agricultura solo era posible en pequeños ecosistemas favorables y, por lo general, no colmaba el abasto local. Sus pobladores también practicaban un sistema de intercambio de algunos excedentes, por medio de trueque o venta, de bienes complementarios para el consumo familiar procedentes de los valles circundantes. La sal, que extraían de la cuenca salitrera que tiene la región, servía para la complementación de recursos y generaba algunos márgenes que les permitía cumplir el pago de sus arriendos. Asociado a la circulación mercantil el servicio de transporte fue también un rubro de actuación directa de los grupos campesinos; desde los primeros años de la dominación colonial se prestaron como arrieros. Por su parte, la actividad minera tenía una tradición colonial forjada por los propios pueblos originarios para afrontar los tributos y la provisión de algunos bienes en el mercado (Gil Montero, 2006).

El departamento de Cochinoca era uno sus principales distritos ganaderos de la Puna y de la provincia. Los datos del censo de 1895 permiten ubicarlo como

\footnotetext{
${ }^{14}$ AHJ. Fondo Caja Documentos 2, año 1887, Informe Presentado al Gobierno en los recuentos de intereses fiscales de la Quebrada y Puna, 25 de mayo de 1887.

${ }^{15}$ AHJ. Fondo Caja de expedientes, Vecinos de Cochinoca, Expte. 7 V, Jujuy, 23 de octubre de 1913.
} 
el principal productor caprino (reunía el $28 \%$ del stock provincial) y asnal (33\% del total); el segundo en relevancia por la cría de ovino (con el $20 \%$ total), mucha menor significación del vacuno (2\%) y una importante presencia de llamas, con unas 6.588 cabezas. ${ }^{16}$ Hacia el interior del departamento, la importancia de la producción ovina era elocuente pero el ritmo productivo fue decreciente a lo largo del siglo XIX.

Sabemos que el comercio de la Puna estaba articulado desde la época colonial al espacio económico peruano, y pese a la paralización sufrida por la Revolución y la Guerra, pasado el medio siglo XIX, mantenía su vigencia:

Sus principales artículos de exportación son el charque de
ovejas y llama a los minerales próximos a Bolivia [...]; el sebo
también a Bolivia [...], ganado en pie, burros y ovejas a la
misma plaza [...], la mayor parte de ellos a Atacama y Caracoles
(Bolivia) [...] Las lanas de ovejas así como las de llamas y
animales silvestres que cazan, son también objeto de comercio,
pero en pequeña escala, porque como su ocupación principal
es el pastoreo, se entretienen también en hilar para fabricar sus
tejidos, conocidos con el nombre de picota o barchilla, las que
son de exportación a Tarija, de donde en cambio traen maíz,
negocio que también lo hacen con este Departamento (el de
San Salvador de Jujuy) y la Quebrada de Humahuaca. ${ }^{17}$

Con este panorama como telón de fondo en el siglo XIX, nos queda pendiente mostrar algunos indicios de la surte seguida en los niveles de vida, a partir de análisis de la distribución de la riqueza.

\section{La riqueza de los arrenderos}

¿Qué niveles de riqueza material alcanzaban los sectores arrendatarios? ¿Qué contrastes hubo en las estratificaciones sociales de Cochinoca y en las posibilidades de acumulación y movilidad social cuando regían derechos de propiedad fiscal, a cuando imperaba el dominio privado del Marquesado de Tojo? Estos constituyen los dos interrogantes centrales de este último apartado. En el censo económico de 1895 que hemos consultado, figura muy bien el perfil de una población local mayoritariamente compuesta por arrendatarios; y el peso de la actividad pastoril, de una ganadería extensiva, diversificada en crías ovinas, caprinas, asnales y de llamas; con pocas explotaciones agrícolas de pequeña escala y de subsistencia. Solo a un 3\% de los actores de Cochinoca consignados en el censo de población y de ganadería le corresponde la categoría de propietarios. Es preciso indicar que las primeras compras de estas tierras

\footnotetext{
${ }^{16}$ AGN. Segundo Censo Nacional, año 1895, Cédulas censales, Boletín de ganadería, N 30, Departamento Cochinoca, fs. 85.

${ }^{17}$ Informe de la Inspección Nacional de Agricultura en la Provincia de Jujuy, 1875, p 324.
} 
Fandos. Niveles de vida de los arrendatarios de Cochinoca (Jujuy). Entre el dominio del Marquesado de Tojo...

efectuadas en subasta pública datan de finales del año 1895, por lo tanto, este proceso de transferencia es posterior al censo levantado en mayo de ese año, pilar de nuestro análisis. Por su parte, la referencia sobre producción agrícola en esta fuente es muy escueta, apenas unos 13 productores de unas 13 cuadras cuadradas, 12 de alfalfa y una de cebada, circunscripta a la zona de Quera, Chipaite y Cerro Blanco, todos en condición de "arrendatarios fiscales". ${ }^{18}$ En el censo de 1864, todos los censados eran arrendatarios de la propiedad de Cochinoca de Campero y no hay ningún registro de actividad agrícola.

Tabla 2. Departamento Cochinoca. Distribución de la riqueza ganadera de los arrendatarios (1864- 1895)

\begin{tabular}{|c|c|c|c|c|c|c|c|}
\hline Etapa & $\begin{array}{c}\mathrm{N}^{\circ} \text { de } \\
\text { Criadores }\end{array}$ & $\begin{array}{c}\mathrm{N}^{\circ} \text { de } \\
\text { Familias }\end{array}$ & $\begin{array}{c}\mathrm{N}^{\circ} \text { de } \\
\text { Individuos }\end{array}$ & $\begin{array}{l}\text { Total del capital } \\
\text { ganadero }\end{array}$ & GINI/ UC* & $\mathrm{GINI} / \mathrm{P}^{* *}$ & $\begin{array}{c}\text { Relación } \\
\text { 20-20 }\end{array}$ \\
\hline 1864 & 345 & 377 & 1599 & $\begin{array}{c}252.216 \text { peso } \\
\text { boliviano }\end{array}$ & 0,5348 & 0,4916 & $54,0 / 2,93$ \\
\hline 1895 & 771 & 808 & 3741 & $\begin{array}{c}815.548 \\
\text { peso nacional }\end{array}$ & 0,4962 & 0,4705 & $\begin{array}{l}49,7 / 3,82 \\
50,5 / 3,72\end{array}$ \\
\hline
\end{tabular}

Fuente: elaboración propia sobre la base de AHJ. Fondo Caja Documento, año 1865, Censo de Cochinoca, 13 de enero de 1865. AGN, Segundo Censo Nacional, año 1895, Cédulas censales, Legajo 180, Provincia de Jujuy, Boletín de ganadería, N³0, Departamento de Cochinoca, fs. 1 a 85. Cédulas censales, Segundo Censo Nacional, Población, Argentina, 1895, Provincia de Jujuy, Departamentos de Cochinoca [on line] http://search.labs.familysearch.org.

* Se contempla la distribución de riqueza ganadera en relación a todas las unidades familiares que poblaba Cochinoca en cada año, respectivamente.

** Es el cálculo de distribución en proporción a los productores de ganado.

Dentro de los parámetros de distribución de la riqueza ganadera que se manejan para otras sociedades argentinas del siglo XIX, esta tabla revela un índice de desigualdad bastante equilibrado. Claro que los valores de la década de 1860 ocultan el fuerte desequilibrio que provocaba el monopolio absoluto sobre toda la superficie territorial de Cochinoca en manos de los Campero, esa propiedad estaba valuada en 1872 en 80.000 pesos bolivianos (equivalente a un $32 \%$ del total de capital que en conjunto congregaban los arrendatarios por propiedad de ganado en ese momento), ya dijimos que se calculaba para esa finca en 1875 una renta por arriendos de 8.000 pesos bolivianos, cifra que proporcionalmente representaba el $20 \%$ del total del capital ganadero que reunían sus arrendatarios.

Pero centrándonos solo en los arrendatarios, nuestra primera impresión es que no hubo en el lapso analizado una incidencia considerable de las alteraciones en los derechos de propiedad como suceso fundamental de mejoramiento y/o empeoramiento en los estándares de vida, según el desempeño de la principal actividad económica de estos sujetos. La marcha hacia la etapa en que imperó el dominio fiscal fue apenas más favorable; mediando una fuerte expansión de la planta de productores arrendatarios de

\footnotetext{
${ }^{18}$ AGN, Segundo Censo Nacional, año 1895, Boletín de Agricultura (Cédulas censales), N 27 , fs 1.
} 
la zona (su número se duplicó en 31 años) la desigualdad bajó menos de medio punto. También se suavizó moderadamente la brecha entre los estratos más ricos y más pobres; en 1864 la riqueza del estrato del $20 \%$ más pobre era contenido 15 veces en el que concentraba el grupo del $20 \%$ más rico, esa distancia pasó a ser en 1895 un poco más de 13 veces.

Consideremos otros espacios rurales de Jujuy como referentes de comparación. El primer cotejo es para la década de 1860 y la realizamos con el departamento de Humahuaca. Allí la población arrendataria de mediados del siglo XIX correspondía al $51 \%$ de los hogares existentes y a diferencia de Cochinoca se congregaba en tres haciendas de particulares y las estancias del estado. Las tres haciendas comprendían unidades productivas del tipo y perfil que la finca de Cochinoca en manos de Campero, aunque de mucha menor envergadura tanto por el valor de la tierra (11.000 pesos en total) como por el nivel de producción (y seguramente de renta) de sus arrendatarios. Por su parte, la tierra fiscal fue de más temprana composición en toda la Quebrada de Humahuaca, desde la década de 1830 una vez expropiadas a las comunidades indígenas pasaron a mano pública, y fueron redistribuidas en tenencias agrícolas enfitéuticas y en tierras de usos ganadero y de pastoreo. Estas últimas, llamadas estancias del estado, eran similares productiva y ambientalmente a la de Cochinoca (Fandos, 2014).

Tabla 3. Comparación de riqueza ganadera entre el departamento de Cochinoca y de Humahuaca, década de 1860 (pesos bolivianos)

\begin{tabular}{cccccc}
\hline Unidad Productiva & $\begin{array}{c}\text { Valor de la } \\
\text { tierra }\end{array}$ & $\begin{array}{c}\text { Capital } \\
\text { Ganadero }\end{array}$ & $\begin{array}{c}\mathrm{N}^{\circ} \\
\text { Arrendatarios }\end{array}$ & $\begin{array}{c}\text { Gini } \\
\text { Arrendatarios }\end{array}$ & Gini/UC* $^{*}$ \\
\hline Hacienda de Cochinoca & $\begin{array}{c}80.000 \\
(1872)\end{array}$ & 252.216 & 345 & 0,4916 & 0,5348 \\
\hline Haciendas de Humahuaca & 11.000 & 15.417 & 176 & 0,4578 & 0,6089 \\
\hline $\begin{array}{c}\text { Estancias fiscales } \\
\text { Humahuaca }\end{array}$ & 6.250 & 9.557 & 140 & 0,4832 & \\
\hline
\end{tabular}

Fuente: Elaboración propia sobre la base de AHJ. Fondo Caja Documento, año 1865, Censo de Cochinoca, 13 de enero de 1865 y Fandos, 2014. *El cálculo del Gini sobre las unidades censales para Cochinoca se realizó en base a las casas registradas en las cédulas censales del 1869 (según la fuente ya indicada en el tabla 2); para Humahuaca se tuvo en cuenta el censo local de 1864 . En este censo se registran las casas por separado de los distritos de las haciendas de Tejada (48 hogares), Aguilar (87 hogares) y Negra Muerta (109 hogares), no se diferencian en el relevamiento los parajes comprendidos en las Estancias del Estado (distritos de Mocote, Coraya, Baliazo, Cofradía) cuya población fue agrupada en las localidades de Humahuaca, Aparzo y Uquía, por lo que nos resulta imposible distinguir el número de hogares respectivos. AHJ. Fondo Caja Documento, año 1864, 19 de julio de 1864.

La lectura más evidente de la tabla 3 es el salto de escala en el capital ganadero controlado por los arrendatarios de Cochinoca (en promedio 731 pesos) respecto de las haciendas ( 87 pesos cada uno) y las tierras fiscales (68 pesos per cápita) humahuaqueñas. Desde ese costado del análisis, la riqueza de este conjunto de productores es notablemente superior a los del territorio de la Quebrada. Por otra parte, notamos que las estratificaciones hacia el interior del grupo de arrendatarios en los tres casos resultan bastantes parejas, según los valores del índice de Gini correspondiente: 
Fandos. Niveles de vida de los arrendatarios de Cochinoca (Jujuy). Entre el dominio del Marquesado de Tojo...

0,4 aproximadamente. Al considerar la distribución de la riqueza ganadera entre todas las familias residentes (Gini sobre unidades censales), vemos la agudización de la desigualdad en las haciendas de Humahuaca, respecto de la de los Campero en Cochinoca, que no sufre un salto de escala tan considerable. En realidad, ese mundo más inequitativo en Humahuaca refleja principalmente la realidad de la hacienda de Negra Muerta donde solo el 53\% de los hogares registra riqueza ganadera. Hemos efectuado un testeo nominativo entre el censo de población y el padrón ganadero utilizado para el universo de esta hacienda y detectamos la mayor desigualdad a razón de un conjunto de habitantes que no responde a los patrones más generales de las familias censadas (más extensas, con edades de las parejas superiores a los 30 años, todos criadores). Efectivamente, un grupo importante de los desposeídos de patrimonio ganadero eran hogares de solteros jóvenes (aparentemente hermanos); hogares de parejas muy jóvenes (menos de 25 años), hogares de viudas; y de aquellos que oficiaban en otras ocupaciones (albañil, sombrerero, comerciante y un jornalero).

Para 1895, el paralelo lo podemos marcar para los arrendatarios del departamento de Cochinoca con los de Tilcara (considerando en este caso los que tenían esa condición en distintas fincas particulares). ${ }^{19}$ Los datos de ese cotejo se resumen en la tabla 4, con resultados medianamente análogos en el índice de Gini, con alguna ventaja para el espacio puneño. También resulta más benéfica la situación para el primer departamento en cuanto al capital total que controlaban en sus respectivos espacios estos estratos sociales: en Cochinoca 815.548 pesos y en Tilcara 119.688 pesos. En general, los arrendatarios eran más ricos en Cochinoca que en los otros lugares y unidades de producción, incluso la fracción más pobre de la finca fiscal de la Puna era relativamente más rica en el parangón, ese grupo en Cochinoca congregaba 200 pesos promedio mientras que a similar conglomerado en Tilcara le correspondía 185 pesos cada uno.

Tabla 4. Comparación de la distribución de riqueza entre Cochinoca y otras unidades productivas, 1895 (en pesos nacionales)

\begin{tabular}{cccc}
\hline Lugar & $\begin{array}{c}\text { Propiedad Fiscal de } \\
\text { Cochinoca }\end{array}$ & Departamento de Tilcara & Departamento Cochinoca \\
\hline Rubro & $\begin{array}{c}\text { Riqueza Ganadera de } \\
\text { arrendatarios }\end{array}$ & $\begin{array}{c}\text { Riqueza por ganado de los } \\
\text { arrendatarios }\end{array}$ & $\begin{array}{c}\text { Riqueza por tierras (año } \\
1910)\end{array}$ \\
\hline Gini/UC & 0,4962 & 0,5114 & 0,9535 \\
\hline $\begin{array}{c}\text { Capital } \\
\text { total }\end{array}$ & 815.548 & 135.058 & 731.813 \\
\hline
\end{tabular}

Fuente: elaboración propia sobre la base de AGN, Segundo Censo Nacional, año 1895, Cédulas censales, Legajo 180, Provincia de Jujuy, Boletín de ganadería, $N^{\circ} 30$, Departamento de Cochinoca, fs. 1 a 85 y departamento de Tilcara, fs. 448- 458; Boletín de Agricultura, No 27, departamento Tilcara, fs. $206-2011$. AHJ. Fondo "Catastros de Contribución Territorial", Jujuy, 1910- 1914, departamentos de Yavi, Santa Catalina, Cochinoca y Rinconada, ff.70-101.

\footnotetext{
${ }^{19}$ El cotejo se hace únicamente por la riqueza ganadera de los arrendatarios de haciendas en Tilcara, sin considerar la riqueza agrícola de los mismos.
} 
El último ítem anotado en la tabla 4, que corresponde a otro período (1910), nos permite hacer reflexiones de cómo descompuso el panorama social el hecho de la privatización de la tierra pública en Cochinoca, con las ventas y la nueva distribución que comenzaron a operar desde 1896. Lo que muestra el elevado índice de desigualdad de 1910 es el grado de distribución de los capitales por concepto de propiedad territorial particular en relación a toda la población del departamento; así queda trazado el cuadro de privación de una inmensa mayoría excluida de ese dominio directo y absoluto, que continuó accediendo a la tierra vía arriendo de las fincas privadas y de las pocas que permanecían como fiscales. La desigualdad era extrema, el valor total de la propiedad inmueble continuaba siendo menor que el capital ganadero contabilizado para 1895, pero la riqueza del principal propietario de tierras era catorce veces superior al del principal ganadero y arrendatario fiscal de 1895.

Según una valuación general de los rodeos fiscales sacados en remate en la década de 1890 éstos sumaban 248.083 pesos, el más barato rondaba los mil pesos pero el precio promedio era de 5.168 pesos, ${ }^{20}$ cifra que solo alcanzaban por capital ganadero seis arrendatarios del fisco en 1895. En el proceso de venta, Paz distingue dos intervalos. Uno entre 1893- 1905 en que la mayoría de las ventas se hizo a residentes de la puna u originarios de las tierras. Desde 1905 prevalecieron actores foráneos, originarios de Buenos Aires, con mayores capitales que les permitía la compra sucesiva de más de un rodeo, en muchos casos con fines especulativos (Paz, 1992). Hemos identificado a los actuantes locales en estas compras para develar si hubo una relación posible entre los estándares de arrendatarios y el acceso a la propiedad. El resultado es elocuente en este plano, en esas compras participaron 33 de los arrendatarios del listado de 1895, todos ellos ubicados en el estrato del $20 \%$ más rico por capital ganadero. No obstante, salvo Doroteo Flores, estos actores involucrados en los remates de los rodeos fiscales de Cochinoca adquirieron la tierra a través de copropiedades, constituyendo entre ellos sociedad de compra. ${ }^{21}$

En el interés por develar las condiciones de vida de estos estratos sociales nos preocupa poder determinar de alguna manera la representatividad económica de los patrimonios ganaderos del que disponían. Acabamos de sugerir que no eran ajustados a los precios de las propiedades en remate, por lo tanto el saldo de la principal actividad que desplegaban era insuficiente en ese plano y, seguramente, los alejaba del horizonte de acceso a la propiedad privada. Pero ¿hasta dónde sus posesiones ganaderas los ubicaba o no en situación de pobreza? ¿Era factible que estos arrendatarios lograran niveles de acumulación, cuántos lo alcanzaban?

\footnotetext{
${ }^{20}$ AHLJ. Caja Documento N 42, año 1892, “Anexo C. Tierras fiscales en venta”, marzo de 1892.

${ }^{21}$ Según los datos de venta que aporta Paz, esta fue la modalidad de compra al menos en siete de los rodeos fiscales. Paz prefigura la existencia de otros recursos entre los vecinos y primeros adquirientes de estas tierras, además de los económicos que estamos aportando ahora por concepto de capital ganadero, como los de orden político al mencionar el desempeño de los mismos en algunas funciones públicas locales (Paz, 1992, 229).
} 
Fandos. Niveles de vida de los arrendatarios de Cochinoca (Jujuy). Entre el dominio del Marquesado de Tojo...

Tabla 5. Departamento de Cochinoca. Relación de los criadores según el grado de pobreza, subsistencia y rentabilidad de sus crías. 1864-1895 (cifras absolutas)

\begin{tabular}{|c|c|c|c|}
\hline $\begin{array}{l}\text { Año/ } \\
\text { Escala }\end{array}$ & $\begin{array}{c}\text { Pobreza } \\
\text { (crías inferior a } 50 \\
\text { cabezas de ganado } \\
\text { menor) }\end{array}$ & $\begin{array}{c}\text { Subsistencia } \\
\text { (ganado menor inferior a } 299 \\
\text { cabezas y/o mayor por debajo de } \\
\text { las } 99 \text { cabezas) }\end{array}$ & $\begin{array}{c}\text { Rentabilidad (ganado } \\
\text { ovino superior a } 300 \\
\text { cabezas) }\end{array}$ \\
\hline 1864 & 90 & 238 & 99 \\
\hline 1895 & 136 & 524 & 183 \\
\hline
\end{tabular}

En términos absolutos entre 1864 y 1895 , aumentaron los grupos encuadrados en la línea de pobreza (crecieron un $34 \%$ en la etapa), más incremento tuvieron (50\%) aquellos ubicados entre el mínimo o por debajo nivel de subsistencia; por su parte, los productores con rentabilidad acrecentaron un 46\%. Luego, perduró un perfil de arrendatarios en el límite de los patrones de subsistencia, en cifras cercanas al $70 \%$, tanto cuando la propiedad era detentada como dominio privado de la familia Campero como cuando pasó a manos del Estado. De esa mayoritaria fracción, el nivel de pauperización según los cánones de la época, inferior a la subsistencia, fue mayor en la década de 1860 (26\% de todos los criadores) notándose una ligera mejoría en las proporciones de la franja de pobreza en 1895 ( $18 \%$ del total de criadores). La fracción con márgenes de rentabilidad en la producción ovina se sostuvo en los dos períodos con porcentajes relativos similares, aunque más reducido hacia fines del siglo XIX (en 1895 24\% en relación al $28 \%$ del total de criadores de 1864). Resta decir que entre los sectores ubicados en los segmentos de productores rentables algunos de ellos participaran del juego del mercado de tierras que habilitó el Estado desde 1895 y lograron quedarse con la propiedad de una parcela.

Amén de la crianza y pastoreo de ovino, los animales cargueros en esta región tenían una importancia crucial para el servicio de transporte que desde antaño se ofrecía. Según Holmberg, las llamas y los burros no solo servían para armar tropas propias sino que también se alquilaban. Detallando al "indio carguero", el "indio caminante", el autor señala lo siguiente "por ejemplo cuando bajan a vender la sal, cueros de cabra, de vicuña o tejidos en la Quebrada o en Jujuy, en cuyo caso regresan con las llamas cargadas de maíz o cuando van al sur de Bolivia en busca de los mismos. En caso de no tener llamas de propiedad las alquilan a 0,20 cvos. por día, precio que también pagan por alquiler de burros" (Holmberg, 1904, p. 81). De manera que eran imprescindibles para facilitar y/o sortear los costos de los viajes de intercambio de los que la gran mayoría participaba. En ese plano, debe advertirse que entre las fracciones de arrendatarios más pobres en 1864 el $80 \%$ era propietaria de una tropa inferior a 40 burros y/o llamas, lo que nos indica 
que contaban con este recurso complementario de su escaza producción ovina/caprina, aunque no podamos saber hasta qué punto ello implicaba otra fuente de ingresos para balancear su situación. Del total, el $92 \%$ de todos los productores ganaderos de esa primera etapa reunían tropas menores de los animales cargueros. El mismo patrón se repite en 1895.

Madrazo alude a una tropa de 500 burros como medida de gran escala de la actividad. Para 1864 solo un sujeto era propietario de 463 burros y de ese valor se saltaba al siguiente con 200 cabezas de asnales; mientras que en 1895 no había quien alcance tropa semejante. Si bien los distintos estándares de arrendatarios que hemos clasificado tenían sus tropas, el sector de productores ovinos que alcanzaban pisos de rentabilidad y acumulación también eran los más concentrados criadores de cargueros, denotando en este caso el desarrollo claro de una actividad ganadera integrada al servicio de transporte (arrieros, troperos); así, en 1864 la fracción de criadores con 300 a más cabezas de ovinos, siendo el $28 \%$ del universo de productores, reunía el $52 \%$ de las llamas y cabras existentes en Cochinoca.

\section{Epílogo}

La historiografía regional ha dado sobradas muestras de las grandes diferencias sociales que provocó en Jujuy la fuerte concentración de tierras durante el siglo XIX. Del lado de los sin tierras sabemos ubicar a la gran masa de arrendatarios que imprimieron su sello distintivo en el ámbito rural de las regiones menos dinámicas y más marginales del proceso decimonónico, las tierras altas. Hay pistas bastantes claras del sendero que los condujo a la proletarización para nutrir el trabajo en ingenios y minas. También de la lucha secular que siguieron frente a la privación y control autónomos de los recursos.

A riesgo de reducir lo complejo de las realidades sociales -históricas y presentes- hemos abordado otro fondo del problema, con la intención de generar indicios estadísticos de la situación de vida de este grupo protagónico de la gran historia del capitalismo local. Sin tierras en propiedad, con acceso a través del arriendo ¿con qué bases materiales contaron para sobrevivir? Una pregunta sin duda dificultosa de resolver frente al abanico de fuentes disponibles y la multidimensionalidad del fenómeno. Además, otro interés del estudio fue perseguir el influjo posible del ejercicio de diferentes derechos de propiedad en los niveles de vida.

Lo que el análisis alcanzado comprueba es una aminoración de los patrones de desigualdad en el paso de la posesión de Campero a la propiedad fiscal, que consideramos insustancial como para desprender de ese cambio de condición en los derechos ejercidos un factor de peso objetivo en los niveles de vida material. La base de la riqueza de los arrendatarios de Cochinoca, en una y otra etapa, perfiló un escenario social de productores directos que apenas lograban la subsistencia a partir de su principal ocupación, privándolos también de reunir el mínimo capital equiparable al valor de la tierra, como para acceder a ella en propiedad. Pero, como prueba de las estratificaciones hacia el interior, además de constatarse la existencia de estratos 
Fandos. Niveles de vida de los arrendatarios de Cochinoca (Jujuy). Entre el dominio del Marquesado de Tojo...

concentrados que desarrollaban una ganadería más rentable, hubo a quienes les fue posible sortear la relación del arrendamiento convirtiéndose en dueños de sus propias tierras. El reparto del capital ganadero nunca llegaba a generar las diferencias sociales que sí provocó la concentración de tierras antes de la expropiación de Campero y luego de la privatización de la década de 1890 . No obstante, también es cierto que en el horizonte de las comparaciones que pudimos lograr con otros de sus pares arrendatarios, los de Cochinoca eran considerablemente más ricos.

Una de las principales bondades de los recursos estadísticos aplicados a la indagación de los niveles de vida a través de las estimaciones de riqueza es su potencial comparativo como método para arribar a explicaciones más generales de los procesos históricos, en diferentes escalas. La tarea pendiente es aún inmensa. Es preciso ampliar la pesquisa de otras fisonomías regionales del fenómeno del arrendamiento, con todas las versiones posibles. No debe prescindirse de la búsqueda de los indicadores necesarios en la agenda futura, que afinen los propios componentes para analizar la riqueza producto de las otras actividades desarrolladas (amén de la ganadera) y de aquellos que proporcionen datos sobre los ingresos rurales. Una medida estimativa de los ingresos brutos posibilitaría igualmente trazar con más certeza la gravitación de la renta de la tierra sobre el sector de arrendatarios y de propietarios.

Finalmente, cabe una última reflexión. La tierra que poblaban y que trabajaban desde tiempos inmemoriales fue en el corto plazo de tres décadas propiedad privada particular y luego propiedad pública, para definitivamente volverse a privatizar. Del rescate de algunas prácticas, nos queda la certidumbre de una mayor libertad, permeabilidad y laxitud en los arrendamiento fiscales. A partir de los remates de estas tierras, desde 1896, se volvieron frecuentes las expresiones de añoranza emitidas por sus moradores sobre el arriendo fiscal, decían, "acostumbrados a ese módico impuesto, sin obligación de servicio personal ni restricción a nuestra libertar [...] hemos trabajado casas y rastrojos, hemos puesto alfalfares y demás cosas de nuestra comodidad como si viviéramos en tierras de nuestra propiedad". ${ }^{22}$ El fragmento es elocuente de lo que se resignaba en el traspaso a manos privadas: una carga monetaria considerada justa y legítima, la ausencia de servicios personales, su propia libertad y la impresión del ejercicio de un derecho propio y plural sobre la tierra que habitaban.

Quizás la medida de su bienestar pasaba más por percepciones subjetivas, por otras legitimaciones de orden simbólico, que las dables desde las bases materiales de vida.

\section{Referencias bibliográficas}

Albeck, M. y Palomeque, S. 2009. "Ocupación española de las tierras indígenas de la Puna y "Raya del Tucumán" durante el temprano período colonial". Memoria Americana, 17, 2, Buenos Aire, 173-212.

Córdoba, R. 2007. "Capacidades y libertad. Una aproximación a la teoría de Amrtya Sen". Revista Internacional de Sociología, LXI, 47, España, Instituto de Investigaciones Sociales Avanzado, CSIC, 9-22.

${ }_{22}$ AHJ. Fondo Caja documento, año 1896, Nota elevada por arrenderos fiscales de Abralaite, 18 de junio de 1896. 
Dyer, C. 1998. "La Historia de los niveles de vida en Inglaterra, 1200- 1800. Enfoques y problemas". Historia Agraria, 16, Murcia, SEHA, Universidad de Murcia, 101117.

Fandos, C. y Parolo, M. P. 2011. "La distribución de la riqueza inmobiliaria en el Norte argentino. Tucumán y Jujuy, 1860-1870”. En J. Gelman (Coord.), El mapa de la desigualdad en Argentina del siglo XIX. Rosario: Prohistoria Ediciones, 333-369.

Fandos, C. 2013. "Privatización de la propiedad, riqueza y desigualdad en las "tierras altas” de Jujuy (Argentina), 1870- 1910”. Revista Historia Crítica, 51, Bogotá, Universidad de los Andes, 45-70.

Fandos, C. 2014. "Enfiteutas, propietarios y arrendatarios en el Departamento de Humahuaca. Estructura social y distribución de la riqueza en la década de 1860". Estudios Sociales del NOA, 14, Buenos Aires, UBA, Instituto Interdisciplinario de Tilcara, 41-61.

Fandos, C. 2016. "Privatización de tierras fiscales en la Puna jujeña y réplica indígena: las peticiones de nulidad y denuncia de "malos tratamientos", 1890 a 1920". Revista Cuadernos Series Especiales, III, 1, Buenos Aires, Instituto Nacional de Antropología y Pensamiento Latinoamericano, 98-115.

Fandos, C. 2016. "Arriendo y desigualdad en las tierras altas de Jujuy (Argentina) a fines del siglo XIX”. Revista Anuario de Historia Regional y de las Fronteras, 21, 1, Colombia, Universidad Industrial de Santander, 133-157.

Gelman, J. 2011. El mapa de la desigualdad en la Argentina del siglo XIX. Rosario: Prohistoria Ediciones.

Gil Montero, R. 2005. "Ni indios ni ciudadanos. La población de la Puna a mediados del siglo XIX”. En D. Santamaría (Comp.), Jujuy: arqueología, historia, economía, sociedad (149-172). Jujuy: CEIC.

Gil Montero, R. 2006. "La Puna. Población, recursos y estrategias”. En A. Teruel y M Lagos (Dirs.) Jujuy en la Historia de la colonia al Siglo XX (pp. 373-401). Jujuy: UNIHR/ Ediunju.

Gil Montero, R. 2004. "Población, medio ambiente y economía en la Puna de Jujuy, Argentina, siglo XIX”. Revista de Demografía Histórica, XXII, 1, ADEH, Zaragoza, 185-208.

Hobsbawm, E. 1979. Trabajadores. Estudios de Historia de la Clase Obrera. Barcelona: Crítica.

Holmberg, E. 1904 [1988]. Investigación agrícola en la provincia de Jujuy. Jujuy: UNJu.

Langer, E. y Conti, V. 1991. "Circuitos comerciales tradicionales y cambio económico en los Andes Centromeridionales (1830- 1930). Desarrollo Económico, 31, 121, Buenos Aires, 91-111.

Madrazo, G. 1982. Hacienda y encomienda en los Andes. La Puna de Jujuy bajo el marquesado de Tojo, siglos XVII-XIX. Buenos Aires: Fondo Editorial.

Madrazo, G. 1995. "Historia de un despojo: el indigenado del Noroeste Argentino y su transformación campesina". Revista Andes, 6, Salta, UNSa, CEPIHA, 127-157.

Martínez Carrión, J. 1997. "Los niveles de vida del campesinado en la España Contemporánea". Algunas reflexiones". Historia Agraria, 14, Murcia, SEHA, Universidad de Murcia, 25-57. 
Fandos. Niveles de vida de los arrendatarios de Cochinoca (Jujuy). Entre el dominio del Marquesado de Tojo...

Mörner, M. 1970. El colonato en la América Meridional Andina desde el siglo XVIII Informe preliminar-. Estocolmo: Instituto de Estudios Iberoamericanos.

Palomeque, S. 2000. "Acceso a los recursos y participación mercantil en una zona rural surandina. (Puna de Jujuy, siglo XVIII y XIX)". En J. Silva Riquer y A. Escobar Ohmstede (Coord.) Mercados indigenas en México, Chile y Argentina, siglos XVIII y XIX (pp. 117-210). México: Instituto de Investigaciones José María Luis Mora.

Paz, G. 1991. "Resistencia y rebelión campesina en la Puna de Jujuy, 1850-1875", Boletín del Instituto de Historia Argentina y Americana Dr. Emilio Ravignani, 3-4, Buenos Aires, Instituto de Historia Argentina y Americana Dr. Emilio Ravignani, 63-89.

Paz, G. 1992. "Campesinos, terratenientes y Estado. Control de tierras y conflicto en la Puna a fines del siglo XIX". Sociedad y articulación en las tierras altas jujeñas. Crisis terminal de un modelo de desarrollo (pp. 217-235). En A. Isla (Comp.), Argentina: Ediciones gráficas Mundo Color.

Pérez Picaso, M. T. 2010. "Estructuras agrarias y niveles de vida en la España rural, 18361936. Un balance historiográfico". En G. Chastagnaret, J. Daumas, A. Escudero Gutiérrez, O. Raveux (Eds.) Los niveles de vida en España y Francia (siglos XVIII$X X)$. In memoriam Gérard Gayot. Alicante: Universidad de Alicante, 45-78.

Reboratti, C; Arzebo, M; Castro, H. 2003-2004. "Desarrollo sustentable y estructura agraria en la Quebrada de Humahuaca". Población \& sociedad, 10-11, Tucumán, Instituto Superior de Estudios Sociales, 193-213.

Rutledge, I. 1987. Cambio agrario e integración. El desarrollo del capitalismo en Jujuy. 1550-1960. Tucumán: ECIRA-CICSO.

Sica, G. 2014. "Forasteros, originarios y propietarios en la Quebrada de Humahuaca, Jujuy (siglo XVII y XVIII". Estudios Sociales del NOA, 14, Buenos Aires, UBA, Instituto Interdisciplinario de Tilcara, 15-39.

Teruel, A. 2005. "Estructuras agrarias comparadas: la Puna argentina y el sur boliviano a comienzos del siglo XX". Revista Mundo Agrario, 6, 11, La Plata, Universidad Nacional de La Plata, recuperado de http://www.mundoagrario.unlp.edu.ar/article/ view/v06n11a06/1297.

Teruel, A. 2014. "En torno al conocimiento histórico de los derechos de propiedad de la tierra en la frontera argentino- boliviana". Estudios Sociales del NOA, 14, Buenos Aires, UBA, Instituto Interdisciplinario de Tilcara, 63-86.

Teruel, A. 2016. "El marquesado del valle de Tojo: patrimonio y mayorazgo del siglo XVII al XX en Argentina y Bolivia". Revista de Indias, 76, 265, España, Consejo Superior de Investigaciones Científicas, (en prensa).

Thompson, E. P. 1984. Tradición, revuelta y consciencia de clase. Estudios sobre la crisis de la sociedad preindustrial. Barcelona: Crítica.

Tomasi, J. 2013. "Espacialidades pastoriles en las tierras Altoandinas. Asentamientos y Movilidad en Susques, Puna de Atacama (Jujuy, Argentina)". Revista de Geografia Norte Grande, 55, Chile, Pontifica Universidad Católica de Chile, 67- 87. 